7. Tomczak A, Mortensen JM, Winnenburg R, Liu C, Alessi DT, Swamy V, et al. Interpretation of biological experiments changes with evolution of the Gene Ontology and its annotations. Sci Rep. 2018;23:5115.
8. Mubeen S, Hoyt CT, Gemünd A, Hofmann-Apitius M, Fröhlich H, DomingoFernández D. The impact of pathway database choice on statistical enrichment analysis and predictive modeling. Front Genet. 2019;10:1203.
See Article page 851 .

\section{Commentary: Potential preventive peroxisomal policing of postoperative atrial fibrillation}

\author{
Alden H. Harken, MD
}

The authors ${ }^{1}$ postulate that before coronary artery bypass grafting, pre-existing circulating proteins and metabolites predict the vulnerability of some patients to postoperative atrial fibrillation (POAF). Multiple studies have reported that the presence of POAF is associated with coincident additional postoperative trouble. Therefore, the identification of preoperative markers predicting POAF should both warn clinicians of postoperative challenges but perhaps more importantly suggest a potential target for preoperative pharmacologic preparation of the vulnerable patient.

During the study period, the authors performed 549 coronary artery bypass grafting procedures, of whom 391 patients met the study's inclusion criteria. By matching "the most relevant clinical variables of age, sex and ethnicity..." and including the additional characteristics of body mass index, smoking, hypertension, previous myocardial infarction, left ventricular ejection fraction, and bypass time, their goal was to eliminate, to the extent possible, clinical factors that might provoke POAF other than the putatively culprit circulating proteins and metabolites that the authors were sampling before surgery.

In this analysis, the preoperative dysregulation of peroxisome proliferator-activated receptor (PPAR)-alpha and glutathione pathways bubbled up as predisposing to POAF.

From the UCSF-East Bay (retired), Alamo, Calif.

Disclosures: Author has nothing to disclose with regard to commercial support.

Received for publication Feb 10, 2020; accepted for publication Feb 11, 2020; available ahead of print Feb 21, 2020.

Address for reprints: Alden H. Harken, MD, UCSF-East Bay (retired), 1565 Alamo

Way, Alamo, CA 94595 (E-mail: alden.harken68@gmail.com).

J Thorac Cardiovasc Surg 2021;162:865-6

$0022-5223 / \$ 36.00$

Copyright (c) 2020 Published by Elsevier Inc. on behalf of The American Association for Thoracic Surgery

https://doi.org/10.1016/j.jtcvs.2020.02.062
Check for updates

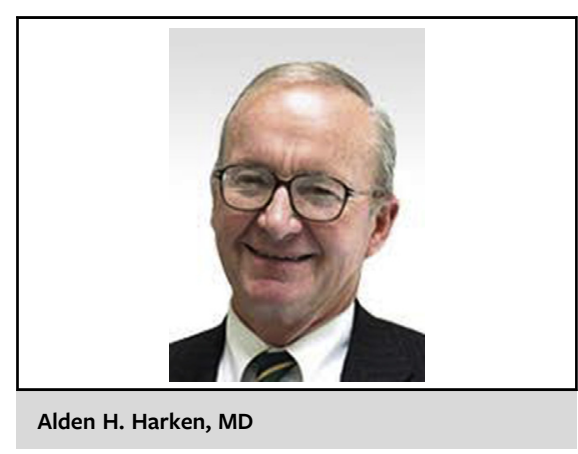

CENTRAL MESSAGE

Dysfunctional peroxisomal antioxidant pathways appear to leave patients vulnerable to postCABG atrial fibrillation.

This finding sort of makes intuitive sense. The circulating PPAR-alpha proteins and glutathione metabolites should reflect 2 of a patient's major strategies of confronting systemic toxic oxygen metabolites. Many, if not most, patients with coronary artery disease experience frequent microinfarctions. When these patients harbor disabled antioxidant policing systems, they should be vulnerable to the heterogeneous patterns of microfibrosis that appear to be essential to the micro-reentry characteristic of POAF.

A peroxisome is a cell membrane organelle that uses oxygen to produce hydrogen peroxide, which is its signaling molecule and from which it derives its name. Peroxisomes also contain a team of antioxidant enzymes that detoxify blood-borne damaging substances. PPARs are nuclear receptor proteins that serve as transcription factors by binding to the promoter region of target genes. PPARs are present in almost all eukaryotic cells, where they both enhance and/or depress gene activity. Glutathione teams up with activated peroxisomes to scavenge toxic oxygen metabolites. 
Some authors have previously reported that diseased cardiomyocyte potassium, chloride, and calcium channels predispose to POAF. These channels are accessible to, and are pacified by, class IIIa antiarrhythmic agents. It may soon be time to offer prophylaxis to patients preoperatively who are inflicted with dysfunctional PPAR $\rightarrow \quad$ and glutathione pathways, with class IIIa sodium channel blocking agents before surgery. It certainly makes intuitive sense.

\section{Reference}

1. Li X-Y, Hou H-T, Chen H-X, Liu X-C, Wang J, Yang Q, He G-W. Preoperative plasma biomarkers associated with atrial fibrillation after coronary artery bypass surgery. J Thorac Cardiovasc Surg. 2021;162:851-63.e3. 